\title{
THE DEVELOPMENT OF A COGNITIVE SKILLS TRAINING TO SUPPORT DRIVER EDUCATION - COMPARING PERFORMANCE OF EXPERIENCED AND TRAINED LEARNER DRIVERS
}

\author{
Tibor Petzoldt, Thomas Weiss, Josef F. Krems \& Maria Bannert \\ Chemnitz University of Technology \\ Chemnitz, Germany \\ Email: tibor.petzoldt@psychologie.tu-chemnitz.de
}

\begin{abstract}
Summary: Deficits in cognitive skills such as hazard perception are considered one of the major factors explaining the high numbers of crashes for novice drivers. Computer based trainings (CBTs) have been identified as a potential measure to improve such skills. Several CBTs have been developed since. Some of them have been evaluated, however, only by comparing a treatment group and a control group. While results show that the evaluated CBTs are somewhat effective, it is unclear how an experienced driver would have performed in the test scenarios. We developed our own CBT, and in a first step, evaluated it following the same known strategy (treatment and control group, adding a "paper based training group). Results provided evidence for the assumption that the CBT had a positive effect on learner drivers' glance behaviour in simulated driving (Petzoldt et al., 2013). However, after we confirmed the effectiveness, we tested a group of experienced drivers on exactly the same simulator scenarios. The comparison between treatment, control and experienced driver group is presented in this paper. Results show comparable patterns of glance behaviour for the treatment group and the experienced drivers, superior to that of the control group. Driving performance rated by experts was mostly appropriate for all groups, with notable exceptions for some scenarios.
\end{abstract}

\section{INTRODUCTION}

According to any national (e.g. Statistisches Bundesamt, 2012) or international (e.g. OECD, 2006) statistic, young drivers are at an increased risk on the road. While part of the problem stems from age related social and individual circumstances (e.g. Gregersen \& Bjurulf, 1996), the lack of driving experience, reflected by deficits especially in driving relevant cognitive skills, is just as crucial. Research on hazard perception (e.g. Crick \& McKenna, 1992; Mills, Hall, McDonald, \& Rolls, 1998; Whelan et al., 2004), risk evaluation (Finn \& Bragg, 1986), the assessment of driving skills (Matthews \& Moran, 1986; Groeger \& Brown, 1989), or calibration (the balancing of task demands and capabilities; Kuiken \& Twisk, 2001) provide rich evidence for this assumption.

One option to address these issues are computer based trainings (CBTs). Applications like Driver ZED (Blank \& McCord, 1998), DriveSmart (Regan, Triggs, \& Wallace, 1999) or CDDrives (Cockerton \& Isler, 2003; Isler \& Cockerton, 2003) use real life video footage and require the users to answer multiple choice questions, to react to hazards by pressing buttons, or to mark hazardous areas in the scenery. Evaluations of these applications (Fisher et al., 2002; Regan, Triggs, \& Godley, 2000) show that there are indeed measurable effects. However, to our 
knowledge, none of the available evaluations compared performance of CBT trained learner drivers to the performance of experienced drivers. So, while some effect has been found, it is unclear how this "improved" behaviour relates to the behaviour of experienced drivers. We developed our own CBT (see "Computer based training”), and in a first step, tested its effects against a control group and a paper based training (Petzoldt et al., 2013). Results provided further evidence for the potential of CBTs. In a second step, which is reported here, we set out to compare our CBT groups’ performance on the test scenarios to a group of experienced drivers.

\section{The computer based training}

Goal of our CBT is to support the development of appropriate glance patterns to acquire all the relevant information in a traffic situation, but also to help interpret this traffic situation based on the information perceived. The application consists of three parts: (1) a pre-test on theoretical knowledge, (2) an instructional phase, and (3) the actual training. The training uses short clips of traffic scenes, embedded in a Flash environment. To create relevant traffic scenes, we generated artificial animations, similar to a driving simulation. The participants watch them from the driver's point of view. Scenes were constructed to reflect one crucial handicap of novice drivers the close focus on an area directly in front of the vehicle, neglecting the farther vertical and horizontal areas (e.g. Mourant \& Rockwell, 1972). They include various aspects of the driving task - car following situations, passing/overtaking, being overtaken, passing through intersections, or turning left or right.

The scenes are stopped at various positions and questions are presented. Most questions are in multiple-choice format, some also require the participants to mark certain relevant areas in the stopped video. Depending on whether the given answer is correct or not, participants receive feedback, followed by either the continuation of the sequence or the repetition of the previous segment of the scene (in case of a wrong answer). Questions vary in content - they require the observation of the traffic environment as well as the understanding and prediction of traffic situations, up to the point where relevant actions are queried. The training comprises two different parts which can be completed separately. Both contain 13 video sequences, with two or three questions for each sequence. Video sequences are 50-70 sec in length.

\section{METHOD}

To assess not only whether the developed CBT has positive effects on a novice driver's abilities, but also how these effects relate to experienced drivers behaviour, we employed a simple onefactorial between-subjects design. Participants were either learner drivers that (a) completed the aforementioned CBT of cognitive driving skills or (b) served as a control group without any learning intervention, or (c) were experienced drivers. The central dependent variable for the assessment of learning effects was participants' glance behaviour in a subsequent driving simulator test. The method is described in detail in Petzoldt et al. (2013).

\section{Participants}

The two learner drivers groups consisted of students at driving schools. Only students without other licenses previously acquired (e.g. motorcycle) and with a maximum of four practical 
driving lessons were allowed to take part. The experienced driver group (selected out of a pool of people regularly participating in our studies, with no affiliation to the university) was required to have an overall driving experience of at least $20,000 \mathrm{~km}$, and was limited to a maximum age of 30 years. Overall, we recruited 60 participants. However, since eye tracking was our main source of data, we ended up with 36 usable datasets (eye tracking data was not available for 24 participants due to poor tracking quality). We had 23 usable learner drivers datasets, 12 (6 female, 6 male, mean age $=18.3$ ) of them in the CBT group, 11 (5 female, 6 male, mean age $=$ 17.2) in the control group. Our 13 experienced drivers ( 8 female, 5 male, mean age $=23.3$ ) had an average driving experience of ca. $65,500 \mathrm{~km}(\mathrm{SD}=18,500 \mathrm{~km})$.

\section{Material}

Our main tool was the training application as described above, which was presented on a 19" flat screen. In addition, we administered questionnaires to gather demographic data and find out about the participants motivation, expectations, etc.

Simulator test scenarios were constructed to reflect content that was practiced previously in the CBT. Some scenarios resembled situations included in the training as closely as possible, others shared at least the general relationships between hazard indicator and critical area (see "Analysis"). The focus of the constructed situations was mainly on the early anticipation of potentially dangerous situations. These situations could, if interpreted correctly, be easily negotiated by slowing down sufficiently or changing lanes early enough to avoid possible conflicts. We did not intend to create situations in which mostly unexpected events require immediate and extreme reactions (e.g. emergency braking), but rather scenarios that are easily navigated by an experienced driver with sufficient anticipatory skills, but might cause inexperienced drivers some difficulties.

\section{Procedure}

All three groups were required to attend two lab sessions. The CBT group filled in questionnaires, completed the pretest on theoretical knowledge, and completed the two parts of the training, with a 20 min break in between. Overall, this session took approximately 120 min to complete. The control group and the experienced drivers only completed the questionnaires in about 20 min. Two days later, participants were tested in the driving simulator. First, they completed a battery of tests (e.g. Ishihara test, paper folding test). Then, they received instructions regarding control of the simulation vehicle, followed by a short practice drive. The eye-tracking system (SMI IView X HED - head mounted) was introduced and calibrated. After calibration, participants drove through the test scenarios. The typical duration of the simulator test was from 90 to $120 \mathrm{~min}$.

\section{Analysis}

Glance behaviour served as the main dependent variable, following the definition of key glance behaviour as characterised by "the participant making at least one fixation on an appropriate region of the environment within a certain temporal window" (Pollatsek et al., 2006; p. 458). As evidence for understanding the potentially hazardous situation, we considered a glance sequence 
from an unspecific hazard indicator (e.g. a gas station ahead) directly to an area where experienced drivers would be looking if they understood the meaning of this unspecific hazard indicator (e.g. lead vehicle that might or might not turn right to enter the gas station). The time between the occurrence of the hazard indicator and the first completion of the glance sequence was measured, assuming that a learning effect would be reflected by an earlier completion of the sequence (Müsseler et al., 2009).

In addition, we used expert ratings of how participants handled the different situations as an additional indicator of potential learning effects. Raters (one rater who did the complete coding, another rater who coded random samples, which were compared to and discussed with the main rater) were unaware of the participants' group assignment / membership. Participants' performance was rated as either (i) optimal, (ii) appropriate but suboptimal, or (iii) inappropriate. For example, in a situation in which the right lane ahead might be blocked by stopped vehicles (e.g. waiting to enter the gas station), optimal would be an early change to the left lane, as this would allow for an uninterrupted onward journey. Braking to come to a halt behind the stopped vehicles is not optimal, but still appropriate. Striking the stopped vehicles is, obviously, inappropriate. We are aware that this form of judgment of performance is rather subjective, but it still can serve as a broad indicator of whether the training had effects that go beyond glance behaviour.

\section{RESULTS}

To better visualise results, we considered the control group as a form of baseline in terms of completion of the critical glance sequence, and plotted the performance of the other groups as differences from this baseline (hence the negative values - see Figure 1). There appears to be a striking resemblance between the patterns for the CBT group and the experienced drivers, both of which were faster to complete the required glance sequence than the control group in most situations. An ANOVA showed a significant effect for the group factor, $F(2,33)=4.23, p=$ $.023, \eta^{2}=.20$. Pairwise comparisons (LSD-corrected) revealed significant differences between the control group and the other two $(\mathrm{CBT}: \mathrm{p}=.022, \mathrm{~d}=1.05$; experienced drivers: $\mathrm{p}=.012, \mathrm{~d}=$ 1.14). There was no significant difference between the CBT group and the experienced drivers ( $p$ $=.825, \mathrm{~d}=.09$ ).

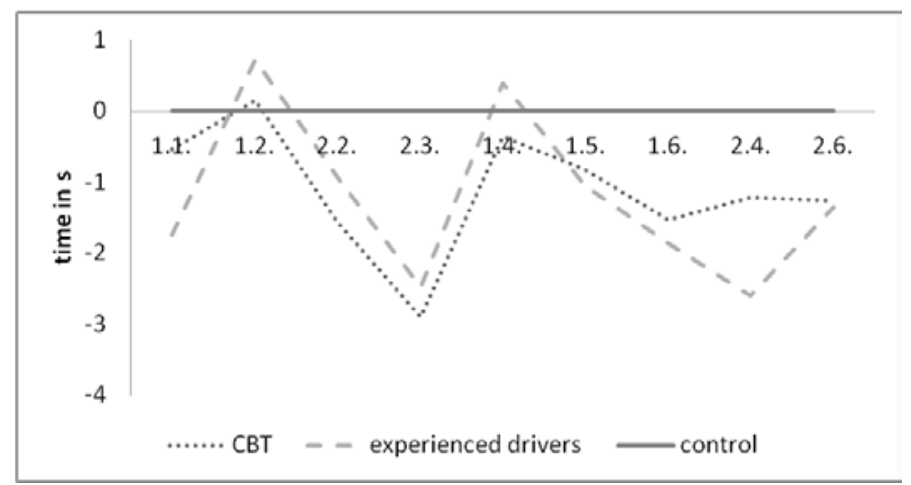

Figure 1. Difference in time until completion of relevant glance sequence compared to control group, separate for each situation (numbers on $\mathrm{x}$-axis indicate situation) 
For the performance rating, the results are less clear. In six of the analysed situations, we found no differences between the groups. Basically all participants handled these situations quite well overall (with few, unsystematic exceptions). However, for the three remaining situations, the results were rather different (see Figure 2). The experienced drivers clearly outperformed the novice drivers, as the majority showed optimal behaviour, with the rest at least handling the situations appropriately. The CBT group's percentage for optimal handling of the situations was at or below $50 \%$, but still visibly higher than for the control group.

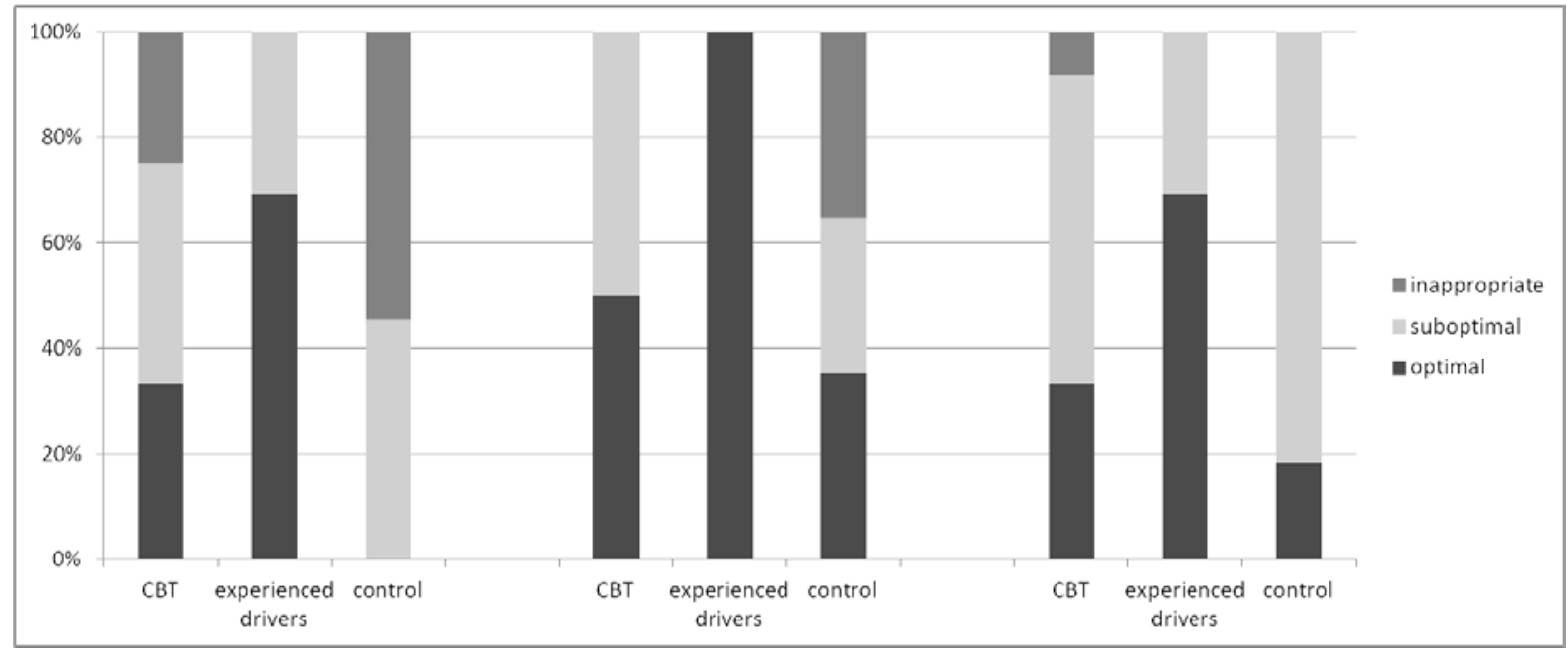

Figure 2. Performance as rated by experts for situations "Congestion on gas station (into driver's lane), lead vehicle brakes" (situation 2.2., left), "Bus stopped on opposite lane, pedestrian quickly approaching from the right" (situation 1.4., centre) and "Turning right into minor road, cyclist about to cross that road" (situation 2.6., right)

\section{DISCUSSION}

The results of our experimental study support the assumption that CBTs can have positive effects that indeed bring learner drivers closer to the performance of experienced drivers. This appears to be especially true for glance behaviour. Both CBT users and experienced drivers were overall much faster to complete critical glance sequences compared to a control group of learner drivers. Moreover, the patterns of results for the different test scenarios are strikingly similar for the CBT group and the experienced drivers. The driving performance as rated by experts, however, does not provide the same clear results. For most situations, we found no differences between the three groups. Even the control group showed optimal behaviour, which did not leave much room for improvement for the CBT group. Still, the pattern of results for three of the situations is interesting. While the CBT appeared to have some positive effect on learner drivers in these situations, experienced drivers' performed considerably better. This disparity between the effects on glance behaviour and rated performance seems reasonable. Although the virtual environment of the CBT is not exactly realistic, it still allows for the actual training of glance behaviour. In contrast, driving performance in the sense of actual behaviour (braking, swerving etc.) is not trained. Though there are items included in the CBT that address certain relevant actions in various driving situations, the response they require (answering a multiple choice question) is, obviously, not realistic. As later stages of training do require higher levels of realism (e.g. 
Wallace, Haworth, \& Regan, 2005), it might seem that whereas for glance behaviour a CBT that mainly relies on multiple choice questions can be beneficial, for actual driving behaviour a higher level of realism, e.g. in terms of interaction with the CBT (by steering, braking etc.), is necessary.

\section{ACKNOWLEDGMENTS}

This research was sponsored by the Bundesanstalt fuer Strassenwesen (BASt; German Federal Highway Research Institute) as project FE82.306/2006 - "Unterstützung der Fahrausbildung durch Fahrsimulatoren und Lernsoftware" / "Supporting driver education with driving simulators and computer based training” (Petzoldt et al., 2011). The tool used for creating video sequences included in multimedia training was provided by TUEV/DEKRA arge tp 21.

\section{REFERENCES}

Blank, D., \& McCord, R. (1998). Design and presentation of a CD-ROM driving program (Driver-ZED). Proceedings of the Human Factors and Ergonomics Society $42^{\text {nd }}$ Annual Meeting, Santa Monica, CA., (pp. 1401-1402).

Cockerton, C., \& Isler, R. (2003). Developing real-life driving simulations for novice driver education. In D. Lassner \& C. McNaught (Eds.), Proceedings of World Conference on Educational Multimedia, Hypermedia and Telecommunications 2003 (pp. 316-317). Chesapeake, VA: AACE.

Crick, J., \& McKenna, F. P. (1992). Hazard perception: Can it be trained? Behavioural Research in Road Safety, 2, 100-107.

Finn, P., \& Bragg, B. W. (1986). Perception of the risk of an accident by young and older drivers. Accident Analysis \& Prevention, 18(4), 289-298.

Fisher, D. L., Laurie, N. E., Glaser, R., Connerney, K., Pollatsek, A., Duffy, S. A., et al. (2002). Use of a fixed-base driving simulator to evaluate the effects of experience and PC-based risk awareness training on drivers' decisions. Human Factors, 44(2), 287-302.

Groeger, J. A., \& Brown, I. D. (1989). Assessing one's own and others' driving ability: Influences of sex, age, and experience. Accident Analysis \& Prevention, 21(2), 155-168.

Isler, R., \& Cockerton, C. (2003). A computer-based interactive multimedia training CD-ROM for novice drivers in New Zealand. In D. Lassner \& C. McNaught (Eds.), Proceedings of World Conference on Educational Multimedia, Hypermedia and Telecommunications 2003 (pp. 799-800). Chesapeake, VA: AACE.

Kuiken, M. J., \& Twisk, D. (2001). Safe driving and the training of calibration: A literature review. (Report no. R-2001-29). SWOV Institute for Road Safety Research, Leidschendam, the Netherlands.

Matthews, M. L., \& Moran, A. R. (1986). Age differences in male drivers' perception of accident risk: The role of perceived driving ability. Accident Analysis \& Prevention, 18(4), 299-313.

Mills, K. L., Hall, R. D., McDonald, M., \& Rolls, G. W. P. (1998). The effects of hazard perception training on the development of novice driver skills. UK Department of the Environment, Transport, and the Regions (DETR), London. 
Mourant, R. R., \& Rockwell, T. H. (1972). Strategies of visual search by novice and experienced drivers. Human Factors, 14, 325-335.

Müsseler, J., Debus, G., Huestegge, L., Anders, S., \& Skottke, E.-M. (2009). Maßnahmen zur Verbesserung der visuellen Orientierungsleistung bei Fahranfängern. Berichte der Bundesanstalt für Straßenwesen, Reihe M (Mensch und Sicherheit), Heft 199.

Organisation for Economic Co-operation and Development (OECD) (2006). Young drivers: The road to safety. Paris, France.

Petzoldt, T., Weiss, T., Franke, T., Krems, J. F., \& Bannert, M. (2011). Unterstützung der Fahrausbildung durch Lernsoftware. Berichte der Bundesanstalt für Straßenwesen, Reihe M (Mensch und Sicherheit), Heft 219.

Petzoldt, T., Weiss, T., Franke, T., Krems, J.F., \& Bannert, M. (2013). Can driver education be improved by computer based training of cognitive skills? Accident Analysis and Prevention, 50, 1185-1192. dx.doi.org/10.1016/j.aap.2012.09.016

Pollatsek, A., Narayanaan, V., Pradhan, A., \& Fisher, D. (2006). Using eye movements to evaluate a PC-based risk awareness and perception training program on a driving simulator. Human Factors, 48 (3), 447-464.

Regan, M. A., Triggs, T. J., \& Godley, S. T. (2000). Simulator-based evaluation of the DriveSmart novice driver CD-ROM training product. Proceedings of the Road Safety Research, Policing and Education 2000 Conference, Brisbane, Australia.

Regan, M. A., Triggs, T. J., \& Wallace, P. R. (1999). ACD ROM product for enhancing perceptual and cognitive skills in novice car drivers. Proceedings of the 1st International Conference on Novice Driver Issues.

Statistisches Bundesamt (2012). Verkehrsunfaelle: Unfaelle von 18- bis 24-Jaehrigen im Strassenverkehr 2011. Wiesbaden, Germany.

Wallace, P., Haworth, N., \& Regan, M. (2005). Best training methods for teaching hazard perception and responding by motorcyclists. Report No. 236, Monash University Accident Research Center.

Whelan, M., Senserrick, T., Groeger, J., Triggs, T., \& Hosking, S. (2004). Learner driver experience project. Report No. 234, Monash University Accident Research Center. 